\title{
Bioactivity guided fractionation and hypolipidemic property of a novel HMG-CoA reductase inhibitor from Ficus virens Ait
}

\author{
Danish lqbal', M Salman Khan ${ }^{1 *}$, Mohd Sajid Khan ${ }^{1}$, Saheem Ahmad ${ }^{1}$, Md Sarfaraj Hussain ${ }^{2}$ and Mohd Ali $^{3}$
}

\begin{abstract}
Background: The current perspective for the search of 3-hydroxy-3-methyl-glutaryl-coenzyme A (HMG-CoA) reductase inhibitor has been shifted towards a natural agent also having antioxidant property. Thus, this study was intended to isolate and identify the bioactive compounds from methanolic extract of Ficus virens bark (FVBM) and to evaluate their antioxidant, HMG-CoA reductase inhibitory and hypolipidemic activity.

Methods: Bioactivity guided fractionation and isolation of bioactive compound from FVBM extract has been done to isolate and characterize the potent HMG-CoA reductase (HMGR) inhibitor with antioxidant activity by using repeated extensive column chromatography followed by spectroscopic methods, including Infrared (IR), ${ }^{1} \mathrm{H}$ \& ${ }^{13} \mathrm{C}$ nuclear magnetic resonance (NMR) and Mass spectrum analysis. The in vitro HMGR inhibition and enzyme kinetic assay was determined using HMG-CoA as substrate. In addition, antioxidant activity of the new isolated compound, was measured using 2,2-diphenyl-1-picrylhydrazyl (DPPH) radical scavenging assay and FRAP value. In-silico molecular informatics of HMGR enzyme type inhibition and pharmacokinetics data of the new compound was further evaluated through molecular docking and ADME-T studies. Further, in-vivo hypolipidemic property of FVBM extract and newly isolated compound was also analyzed in triton-WR 1339 induced rats.
\end{abstract}

Results: Thereby, we report the discovery of n-Octadecanyl-O-a-D-glucopyranosyl(6' $\rightarrow$ 1")-O-a-D-glucopyranoside (F18) as a novel HMG-CoA reductase inhibitor with strong antioxidant property. This inhibitor exhibited not only higher free radical scavenging activity but also marked $\mathrm{HMG}-\mathrm{CoA}$ reductase inhibitory activity with an $\mathrm{IC}_{50}$ value of $84 \pm 2.8 \mathrm{ng} / \mathrm{ml}$. This inhibitory activity concurred with kinetic study that showed inhibition constant $\left(K_{\mathrm{i}}\right)$ of $84 \mathrm{ng} / \mathrm{ml}$ via an uncompetitive mode of inhibition. The inhibition was also corroborated by molecular docking analysis and in silico pharmacokinetics data. The in vivo study revealed that administration of FVBM extract (at higher dose, $100 \mathrm{mg} / \mathrm{rat}$ ) and the inhibitor (1 mg/rat) to Triton WR-1339-induced hyperlipidemic rats significantly ameliorated the altered levels of plasma lipids and lipoproteins including hepatic HMG-CoA reductase activity; this effect was comparable to the effect of standard drug atorvastatin.

Conclusions: The in vitro, in silico and in vivo results clearly demonstrated the antioxidant potential and therapeutic efficacy of the inhibitor as an alternate drug against hyperlipidemia.

Keywords: Ficus virens, Hyperlipidemia, Antioxidant, HMG-CoA reductase, Molecular Docking, Inhibitor

\footnotetext{
* Correspondence: contactskhan@gmail.com

${ }^{1}$ Department of Biosciences, Clinical Biochemistry \& Natural Product Research

Lab, Integral University, Lucknow 226026, India

Full list of author information is available at the end of the article
} 


\section{Background}

Cardiovascular disease (CVD) is the major cause of death in developed and developing countries [1,2]. It is well known that three major risk factors for CVD are hypercholesterolemia, smoking and hypertension [3]. Several studies have established that elevated blood cholesterol along with triglyceride (TG) level is a major cause and initial risk factor of atherosclerosis and subsequent CVD [4,5]. Endogenous cholesterol biosynthesis in the liver is mainly controlled by rate limiting enzyme, 3-hydroxy-3-methylglutaryl-CoA (HMG-CoA) reductase, which catalyzes the conversion of HMG-CoA to mevalonic acid [6]. Drugs that lower cholesterol level mainly work by inhibiting the HMG-CoA reductase activity $[7,8]$. Despite the significant clinical benefits provided by statins [9], many patients do not achieve the recommended low-density lipoprotein (LDL) and high-density lipoprotein (HDL) cholesterol target goals [10]. Moreover, elevated lipid level results in accumulation of LDL in subendothelial space of arteries, where it undergoes through an oxidative modification to form oxidized LDL, which is highly atherogenic [5,11]. Moreover, the use of statins is not preferred in more than $40 \%$ of patients, mostly due to the occurrence of several side effects including myalgia, myopathy, liver disease, and rhabdomyolysis in more severe cases $[12,13]$. Statins in combination with fibrates show significant benefit at higher doses but are also associated with severe side effects [14]. This limits the use of statins and incites a search of new natural drugs to combat hypercholesterolemia as well as cholesterol induced oxidative stress and atherosclerosis.

Medicinal plants are potential sources of therapeutic compounds. Therefore, searching for natural and selective HMG-CoA reductase inhibitors with antioxidant property as an alternative to synthetic drugs is of great interest. One of the promising breakthroughs in the drug discovery is the use of mechanism-based screening for a bioassay guided fractionation such as isolation of mevastatin from Penicillium citrinum $[15,16]$. Ficus virens Ait (FV) (Moraceae) has been known traditionally for its medicinal properties, which include its use in the treatment of blood diseases, uterus, burning sensation, hallucination, and unconsciousness [17]. This plant is also known to possess significant amount of phenolic compounds and a potent antioxidant activity $[18,19]$. In a continuous bid to search new hypolipidemic drug with antioxidant property from plant origin, we have recently demonstrated that among all sequentially extracted fractions of Ficus virens, Ficus virens bark methanolic extract (FVBM) posses a significant HMG-CoA reductase inhibitory activity along with antioxidant property [20]. On this basis, the present study was premeditated to isolate and characterize the bioactive compounds from
FVBM extract, and subsequently to evaluate their antioxidant and HMG-CoA reductase inhibitory activity using in vitro and in silico approaches. Furthermore, in vivo lipid lowering activity and the possible mechanism of action of FVBM extract and the bioactive compound have also been discussed.

\section{Materials and methods \\ Chemical reagents}

HMG-CoA reductase assay kit was purchased from Sigma-Aldrich Co. (USA). 2, 2-diphenyl-1-picrylhydrazyl (DPPH), Triton WR-1339, 2,4,6-tri(2-pyridyl)-s-triazine (TPTZ), and silica gel (60-120 mesh) were purchased from HiMedia Laboratories, Mumbai, India. Total cholesterol (TC) and triglycerides (TG) kits was procured from Merck Diagnostic (German). All other chemicals and solvents used in this study were of analytical grade.

\section{Plant material and extraction}

The plant material, fresh stem bark of Ficus virens Ait (FVB), was collected from herbal garden of the Department of Pharmacy, Integral University, Lucknow, India. Plant was authenticated by Dr. Tariq Husain of the herbarium division of National Botanical Research Institute, Lucknow, India, and has been deposited in herbarium vide Accession No. 97959. The sequential extraction of FVB was performed to obtain methanolic fraction [20].

\section{Bioactivity guided isolation and characterization of active compound}

The dried residue of FVBM extract was subjected to silica gel (60-120 mesh) column chromatography starting with $\mathrm{CHCl}_{3} / \mathrm{MeOH}(98: 02, \mathrm{v} / \mathrm{v})$ as eluent, followed by a gradient of increasing methanol percentage (i.e., increasing polarity). Twenty fractions (F1-F20) of $200 \mathrm{ml}$ each were collected and tested for antioxidant and HMGCoA reductase inhibitory activity as described below. The most bioactive fraction (F18) was subjected to 1D and $2 \mathrm{D}$ thin layer chromatography (TLC) in order to check the purity and determination of the structure of the bioactive compound by using the following techniques: infrared (IR), ${ }^{1} \mathrm{H}$ and ${ }^{13} \mathrm{C}$ nuclear magnetic resonance (NMR), and mass spectroscopy. The electrospray mass spectra were recorded on THERMO Finnigan LCQ Advantage max ion trap mass spectrometer. The samples $(10 \mu \mathrm{l})$ (dissolved in solvent such as methanol/ acetonitrile/water) were introduced into the ESI source through Finnigan surveyor autosampler. The mobile phase was 90:10 Methanol/ACN: $\mathrm{H}_{2} \mathrm{O}$ flowed at the rate of $250 \mu \mathrm{l} / \mathrm{min}$ by MS pump. Ion spray voltage was set at $5.3 \mathrm{KV}$ and capillary voltage at $34 \mathrm{~V}$. Each MS scan was recorded for to $2.5 \mathrm{~min}$ and the final spectra were average of over 10 scans at peak in TIC. The IR spectra of the antioxidant compounds were recorded on Perkin-Elmer 
spectrophotometer version 10.03.06. ${ }^{1} \mathrm{H}$ NMR and ${ }^{13} \mathrm{C}$ NMR spectra were recorded on BrukerDRX-300, using methanol CD3OD as solvent. 1D and 2D TLC were performed on silica gel $60 \mathrm{~F}_{254}$ aluminum plate.

\section{In vitro antioxidant assays}

The DPPH radical scavenging activity was measured according to the standard method of Williams et al. [21]. Measurement of ferric reducing antioxidant power (FRAP) of the various fractions (F1-F20) was carried out according to the procedure of Benzie and Strain [22] with some modifications [23].

\section{In vitro cell-free assay and kinetic studies of HMG-CoA reductase}

The HMG-CoA reductase assay kit from Sigma-Aldrich (St. Louis, MO, USA) based on the catalytic domain of the human enzyme (recombinant GST fusion protein expressed in E. coli) was used, following the manufacturer's protocol. The kit was used for a rapid screening of all the fractions isolated from FVBM extract and for the identification of the most effective bioactive compound with statin-like activities [20].

In order to determine the mode of inhibition of HMG-CoA reductase enzymatic activity, the NADPH concentration was fixed to $400 \mu \mathrm{M}$ and HMG-CoA was used in the range of $100-500 \mu \mathrm{M}$ in the absence and presence of different concentrations $(10,50,100,500$, $1000 \mathrm{ng} / \mathrm{ml}$ ) of the fraction showing maximum inhibition. Enzyme kinetic parameters $\left(K_{\mathrm{m}}\right.$ and $\left.V_{\max }\right)$, were evaluated using the non-linear regression method based on Michaelis-Menten equation and the type of inhibition was identified using Lineweaver-Burk plot, and $K_{\mathrm{i}}$ was determined by Dixon plot $[24,25]$.

\section{Docking analysis}

Crystallographic structures used in this study for HMGCoA reductase in complex with atorvastatin (PDB ID: $1 \mathrm{HWK}$ ) was retrieved from the Research Collaboratory for Structural Bioinformatics (RCSB) Protein Data Bank (www.pdb.org). The 3D structures of the ligands were prepared with Chembiodraw Ultra 12.0. Ligand-protein docking was performed using AutoDock4.2 program. This program starts with the ligand in an arbitrary conformation and finds favorable dockings in a protein binding site using the Lamarckian genetic algorithm to create a set of possible conformations [26] to dock pravastatin. The software docked the novel compound (F18) isolated from FVBM extract into the catalytic portion of HMG-CoA reductase enzyme using an empirical scoring function based on the free binding energy [27]. After execution of Autodock, several conformations of ligand in complex with the receptor were obtained, which were finally ranked on the basis of binding energy and inhibition constant $\left(K_{\mathrm{i}}\right)$. The resulting conformations were visualized in the discovery studio visualizer (version 3.2).

\section{Absorption, distribution, metabolism, and excretion (ADME) studies}

Pharmacokinetic parameters, such as aqueous solubility [28], blood-brain-barrier (BBB) penetration [29], plasma protein binding (PPB) [30], intestinal absorption [31] and cytochrome P450 inhibition [32] for the compound of most potent fraction (F18) and standard, were determined by using Descriptors algorithm in Accelrys Discovery Studio 3.5 software. Standard levels for ADME parameters are listed in Table 1.

\section{In vivo hypolipidemic experiment Animals}

Male Sprague-Dawley (SD) rats weighing around 100$150 \mathrm{~g}$ were procured from Indian Institute of Toxicology Research Center, Lucknow. The study protocol was approved by Institutional Animal Ethics Committee (IAEC) (registration number: IU/Biotech/project/CPCSEA/13/14). The rats (5 per cage) were housed for one week in the animal house at temperature $21-22^{\circ} \mathrm{C}$ with 12 hour light and dark cycles. The rats were given standard diet and water ad libitum.

\section{Dose preparation}

Sequentially obtained FVBM extracts, the bioactive fraction (F18), and the reference drug atorvastatin were dissolved in $10 \%$ dimethyl sulfoxide (DMSO) at different concentrations and were homogenized with saline. The doses of the extracts were selected on the basis of previously published reports [33,34].

\section{Induction of hyperlipidemia}

Hyperlipidemia was induced in rats by a single intraperitoneal injection of Triton WR-1339 (isooctylpolyoxyethylene phenol) (200 mg/kg body weight) dissolved in $0.9 \%$ saline. After one hour of tritonization, the animals were given food and water ad libitum [35]. Rats in normal control group were injected with saline only. The rats were divided randomly and equally (5 rats in each group) in groups as illustrated in Table 2. The plant extract, bioactive compound (F18) and atorvastatin suspension was administered through gastric intubation in single doses of $0.5 \mathrm{ml} / \mathrm{rat}$, just after the tritonization; and blood was withdrawn after 18 hours [36].

\section{Collection of blood and plasma}

At the end of the experiment, rats in each group were anaesthetized; and blood was collected in heparinized tubes by cardiac puncture. Plasma was separated from blood by centrifugation at 2,500 rpm for $30 \mathrm{~min}$, was aliquoted and stored at either 4 or $-20^{\circ} \mathrm{C}$ for future use. 
Table 1 Standard levels of ADME descriptors from Accelrys Discovery studio 2.5

\begin{tabular}{|c|c|c|c|c|c|c|}
\hline Level & Aqueous Solubility Intensity & Intestinal Absorption Intensity & BBB $^{\mathrm{a}}$ Intensity & $\mathrm{PPB}^{\mathrm{b}} \%$ of binding & CYP450` Value & Hepatotoxicity \\
\hline 0 & Extremely low & Good & Very high & $<90 \%$ & Non inhibitor & Extremely low \\
\hline 1 & No, very low & Moderate & High & $>90 \%$ & Inhibitor & \\
\hline 2 & Yes, low & Low & Medium & $>95 \%$ & & \\
\hline 3 & Yes, good & Very low & Low & & & \\
\hline 4 & Yes, optimal & Undefined & Undefined & & & \\
\hline 5 & No, too soluble & & & & & \\
\hline 6 & Unknown & & & & & \\
\hline
\end{tabular}

$\mathrm{BBB}^{\mathrm{a}}=$ Blood Brain Barrier, $\mathrm{PPB}^{\mathrm{b}}=$ Plasma Protein Binding, $\mathrm{CYP} 450^{\mathrm{C}}=$ Cytochrome P450, Acceptable range of hydrogen bond acceptor $=<10$ and hydrogen

bond donor $=<5$.

\section{Preparation of liver homogenate}

After the experiment, the liver from the rats was promptly excised and chilled in ice-cold saline. After washing with saline, it was blotted and weighed. Each liver was cut into pieces; and $10 \mathrm{~g}$ of wet tissue was homogenized with $90 \mathrm{ml}$ of chilled $0.1 \mathrm{M}$ sodium phosphate buffer, $\mathrm{pH} 7.4$, containing $1.17 \% \mathrm{KCl}$ in a waring blender. The homogenate was centrifuged at 1,000 rpm for $10 \mathrm{~min}$ at $4^{\circ} \mathrm{C}$, and finally was aliquoted and stored at $-20^{\circ} \mathrm{C}$.

\section{Isolation of plasma LDL and HDL}

Isolation of plasma LDL and HDL was carried out as described by Wieland \& Seidel [37] and Patsch et al. [38], respectively.

\section{Determination of plasma triglyceride}

Plasma TG was determined by using enzymatic kit (Merck, India) based on glycerol-3-phosphate oxidase peroxides (GPO-POD) method [39]. The very low density lipoprotein-cholesterol (VLDL-C) in plasma was calculated by dividing plasma TG values $(\mathrm{mg} / \mathrm{dl})$ by a factor of 5 as described by Friedewald et al. [40].

\section{Determination of plasma TC, LDL-C and HDL-C}

Plasma TC, LDL-C and HDL-C were determined by using cholesterol enzymatic kit (Merck, India) based on

Table 2 Protocol for the treatment of triton induce hyperlipidemia in rats

\begin{tabular}{ll}
\hline Group & Treatment/route of administration \\
\hline NC & Solvent system (vehicle) \\
HLC & Hyperlipidemic control \\
FVT-1 & Hyperlipidemic + plant extract (FVBM) $(50 \mathrm{mg} / \mathrm{rat})$ \\
FVT-2 & Hyperlipidemic + plant extract (FVBM) $(100 \mathrm{mg} / \mathrm{rat})$ \\
CT & Hyperlipidemic + bioactive compound (F18) $(1 \mathrm{mg} / \mathrm{rat})$ \\
AT & Hyperlipidemic + standard (atorvastatin) $(1 \mathrm{mg} / \mathrm{rat})$ \\
\hline
\end{tabular}

cholesterol oxidase phenol aminophenazone (CHODPAP) method, and results were expressed as $\mathrm{mg} / \mathrm{dl}$.

\section{Assay of HMG-CoA reductase activity in the liver homogenate}

HMG-CoA reductase enzyme activity in the liver homogenate was estimated indirectly as described by Rao and Ramakrishnan [41]. Fresh 10\% tissue homogenate $(1 \mathrm{~g})$ was mixed with $9 \mathrm{ml}$ of saline arsenate $(0.1 \%$ sodium arsenate in physiological saline); and $10 \mathrm{ml}$ of $5 \%$ perchloric acid was added. It was kept for $5 \mathrm{~min}$ at room temperature and centrifuged at 2,000 rpm for $10 \mathrm{~min}$. One milliliter of the supernatant from each tube was taken out and mixed with $0.5 \mathrm{ml}$ of freshly prepared $1 \mathrm{M}$ aqueous hydroxylamine hydrochloride; whereas, for the assay of HMG-CoA, $0.5 \mathrm{ml}$ of alkaline hydroxylamine hydrochloride was added and mixed. After an incubation of $5 \mathrm{~min}$ at room temperature, $1.5 \mathrm{ml}$ of $0.616 \mathrm{M}$ ferric chloride reagent containing 5.2\% TCA, prepared in $0.65 \mathrm{~N}$ $\mathrm{HCl}$ was added and mixed; and absorbance was read at $540 \mathrm{~nm}$ against a reagent blank using a Biospectrumkinetics spectrophotometer (Eppendorf) after $10 \mathrm{~min}$ of incubation at room temperature.

\section{Lactate dehydrogenase (LDH) assay}

The LDH release assay was performed as per Ahmad et al. [42]. In brief, the platelet rich plasma was obtained from the supernatant resulting from the centrifugation of blood at $200 \mathrm{~g}$ at room temperature. F18 (1 mg) and Atorvastatin (1 mg) were incubated with platelet for $2 \mathrm{~h}$ and the cytotoxicity of the F18 on platelets was measured by the release of lactate dehydrogenase (LDH) from platelets suspension lysed with $1 \%$ Triton X-100 using the commercially available LDH kit (Biomedical Research Services).

\section{Data analysis}

For all assays, samples were analyzed in triplicates, and the results are being expressed as mean $\pm \mathrm{SD}$. $\mathrm{IC}_{50}(50 \%$ inhibitory concentration) was calculated by Origin v. 6.0 
professional software (Origin Lab Corporation, Northampton, MA, USA), and the results were evaluated using one-way analysis of variance (ANOVA) and two tailed Student's $t$-test. Statistically significant values were expressed as ${ }^{*} \mathrm{p}<0.05$, ** $\mathrm{p}<0.01$ and $* * \mathrm{P}<0.001$.

\section{Results}

In continuation to our previous study that illustrated presence of most potent antioxidant and HMG-CoA reductase inhibitory property in FVBM extract [20], the current one deals with isolation of the active compound through bioassay guided fractionation and its characterization through IR, NMR and mass spectrometry. Besides this in vivo hypolipidemic effect of the compound was also evaluated.

\section{In vitro antioxidant property}

Since, the role of free radicals in the pathogenesis of various diseases including atherosclerosis has been well established; the scavenging property of natural agents or drug against free radicals is of utmost importance. Among the eluted FVBM fractions, fraction F18 exhibited significantly higher DPPH radical scavenging activity of $51 \%$ at $5 \mu \mathrm{g} / \mathrm{ml}$ (Figure 1), which was much better than standard ascorbic acid value of $12.77 \%$ at $5 \mu \mathrm{g} / \mathrm{ml}$. Moreover, the ability of these fractions to reduce ferric ions into ferrous form, as an indicative of total antioxidant capacity, were also accessed by FRAP assay. Fraction F18 had significantly higher total antioxidant capacity $\left(3.536 \mu \mathrm{M} \mathrm{Fe} e^{2+} / \mathrm{gm}\right)$ followed by fraction F20 (3.168 $\left.\mu \mathrm{M} \mathrm{Fe}^{2+} / \mathrm{gm}\right)$, while other fractions had remarkably less activity (Figure 2).

\section{In vitro HMG-CoA reductase inhibitory study}

It is well established that cholesterol lowering drugs mainly act by inhibiting the enzymatic activity of HMGCoA reductase. Therefore, in the present study all the eluted fractions were screened for HMG-CoA reductase inhibitory activity following a previously standardized protocol $[20,43]$. Among all the eluted fractions, fraction F6, F15, F18, and F20 showed marked HMG-CoA reductase inhibition activity with $73.3 \%, 85.2 \%, 98.5 \%$ and $98.1 \%$ inhibition, respectively, at $5 \mu \mathrm{g} / \mathrm{ml}$ (Figure 3). The fraction F18 due to better antioxidant activity and antiHMG-CoA reductase property was selected for further study. This fraction has $\mathrm{IC}_{50}$ value of $84 \pm 2.8 \mathrm{ng} / \mathrm{ml}$, while pravastatin exhibits an $\mathrm{IC}_{50}$ value of $70 \mathrm{nM}$ (Figure 4). Furthermore, the mode of inhibition of fraction F18 was also analyzed by double-reciprocal Lineweaver-Burk plot according to Michaelis-Menten kinetics. This fraction demonstrated an uncompetitive mode of inhibition against HMG-CoA reductase (Figure $5 \mathrm{a}$ ). $K_{\mathrm{i}}$ value, determined by Dixon plot, of fraction F18 was $84 \mathrm{ng} / \mathrm{ml}$ (Figure $5 \mathrm{~b}$ ) and concorded with $\mathrm{IC}_{50}$ value, i.e., $84 \pm 2.8 \mathrm{ng} / \mathrm{ml}$.

\section{Identification of the newly isolated bioactive compound}

The bioactive fraction F18 was further subjected to IR, ${ }^{1} \mathrm{H}$ NMR, ${ }^{13} \mathrm{C}$ NMR and mass analysis for its identification and structure determination. The bioactive compound was identified as n-Octadecanyl-O- $\alpha$-D-glucopyranosyl $\left(6^{\prime} \rightarrow 1^{\prime \prime}\right)-\mathrm{O}-\alpha-\mathrm{D}$-glucopyranoside. The ${ }^{1} \mathrm{H}$ NMR data showed that this fraction was approximately $95 \%$ pure. It gave positive Fehling's test for glucoside and showed IR absorption bands for hydroxyl groups (3411, 3345, 3211, $\left.3019 \mathrm{~cm}^{-1}\right)$, ester function $\left(1626 \mathrm{~cm}^{-1}\right)$ and aliphatic chain $\left(756 \mathrm{~cm}^{-1}\right)$. On the basis of mass and ${ }^{13} \mathrm{C}$ NMR spectra, the molecular ion peak was identified at $m / z 594[\mathrm{M}]^{+}$in consistence with the molecular formula of acyl diglucoside, $\mathrm{C}_{30} \mathrm{H}_{58} \mathrm{O}_{11}$ (Figure 6). The ${ }^{1} \mathrm{H}$ NMR spectrum of F-18-FVBM displayed two one-proton doublets at $\delta 5.38$ $(\mathrm{J}=4.2 \mathrm{~Hz})$ and $5.11(\mathrm{~J}=7.0 \mathrm{~Hz})$ assigned to anomeric $\mathrm{H}-1^{\prime}$ and $\mathrm{H}-1^{\prime}$ protons and two two-proton doublets at $\delta 3.34$ $(\mathrm{J}=6.9,9.3 \mathrm{~Hz})$ and $3.09(\mathrm{~J}=7.5,6.6 \mathrm{~Hz})$ respectively, other sugar proton from $\delta 3.96$ to 3.30 , two two-proton triplet at $\delta 3.43(\mathrm{~J}=6.3 \mathrm{~Hz})$ and $1.99(\mathrm{~J}=10.8 \mathrm{~Hz})$ attributed to methylene $\mathrm{H}_{2}-6^{\prime}$ proton adjacent to the ester group, other methylene proton as one proton multiplet from $\delta 4.63$ to



Figure 1 DPPH free radical scavenging activity of different FVBM fractions (F1-F20) and ascorbic acid (AA). Values are represented as Mean $\pm S D(n=3)$. Non-significant ( $n s)$, significantly different at ${ }^{*} P<0.05$, ${ }^{*} P<0.01,{ }^{* *} P<0.001 \mathrm{vs} 0 \mu \mathrm{g} / \mathrm{ml}$. 




Figure 2 Ferric reducing antioxidant power of different FVBM fractions. Values are represented as Mean $\pm S D(n=3)$.

3.44 and two-proton multiplet at $\delta 1.87,1.78$ and as singlet at $\delta 1.62$ and a three proton triplets at $\delta 0.87$ $(\mathrm{J}=6.2 \mathrm{~Hz})$ accounted to $\mathrm{C}-18$ primary methyl protons. The ${ }^{13} \mathrm{C}$ NMR spectrum of fraction F18 exhibited signals for ester carbons at $\delta 171.52(\mathrm{C}-1)$, anomeric carbons at $\delta 103.27\left(\mathrm{C}-1^{\prime}\right)$ and $93.32\left(\mathrm{C}-1^{\prime \prime}\right)$, other sugar carbons between $\delta$ 83.39-62.90, methylene carbons from $\delta 33.88$ to 22.55 and methyl carbon at $\delta 14.61(\mathrm{C}-16)$. The presence of $\mathrm{C}-2^{\prime}$ carbon signal in the deshielded region at $\delta 83.39$ indicated attachment of the second sugar unit at C-2' ${ }^{\prime}$ The absence of any signal beyond $\delta 4.04$ in the ${ }^{1} \mathrm{H}$ NMR spectrum and from $\delta 171.52$ to 103.27 in the ${ }^{13} \mathrm{C}$ NMR spectrum suggested saturated nature of the compound (Additional file 1: Figure S1, Additional file 2: Figure S2, Additional file 3: Figure S3 and Additional file 4: Figure S4). On the basis of this evidence the active compound in fraction F18 was determined as $n$-Octadecanyl-O- $\alpha$-D-glucopyranosyl $\left(6^{\prime} \rightarrow 1^{\prime \prime}\right)-\mathrm{O}-\alpha-\mathrm{D}$-glucopyranoside (Figure 6).
In-silico study of bioactive compound with HMG-CoA reductase To further corroborate our findings, the molecular interaction studies were carried out to find out the plausible ligand-receptor interactions between the inhibitor and HMG-CoA reductase. The docked structures of pravastatin-HMG-CoA reductase were found to be surrounded by $\mathrm{Ser}^{684}$, $\mathrm{Asp}^{690}, \mathrm{Arg}^{590}$, $\mathrm{Lys}^{735}$ and Glu ${ }^{559}$ amino acid residues, which play important role in stabilizing the complex, whereas n-Octadecanyl-O- $\alpha-\mathrm{D}$ glucopyranosyl $\left(6^{\prime} \rightarrow 1^{\prime \prime}\right)-\mathrm{O}-\alpha-\mathrm{D}$-glucopyranoside-HMG-CoA reductase complex involved contributions from residues $\mathrm{Asn}^{755}, \mathrm{Asp}^{765}$, $\mathrm{Lys}^{691}, \mathrm{Glu}^{559}, \mathrm{Gly}^{560}, \mathrm{Ala}^{525}, \mathrm{Arg}^{590}$, which are not from the catalytic domain of HMG-CoA reductase. This observation indicated an uncompetitive mode of inhibition. The non-catalytic site accommodated the compound (Table 3) with a dominant nonelectrostatic energy contribution. The inhibitor showed binding energy of-5.58 Kcal/mol indicating high affinity for the binding

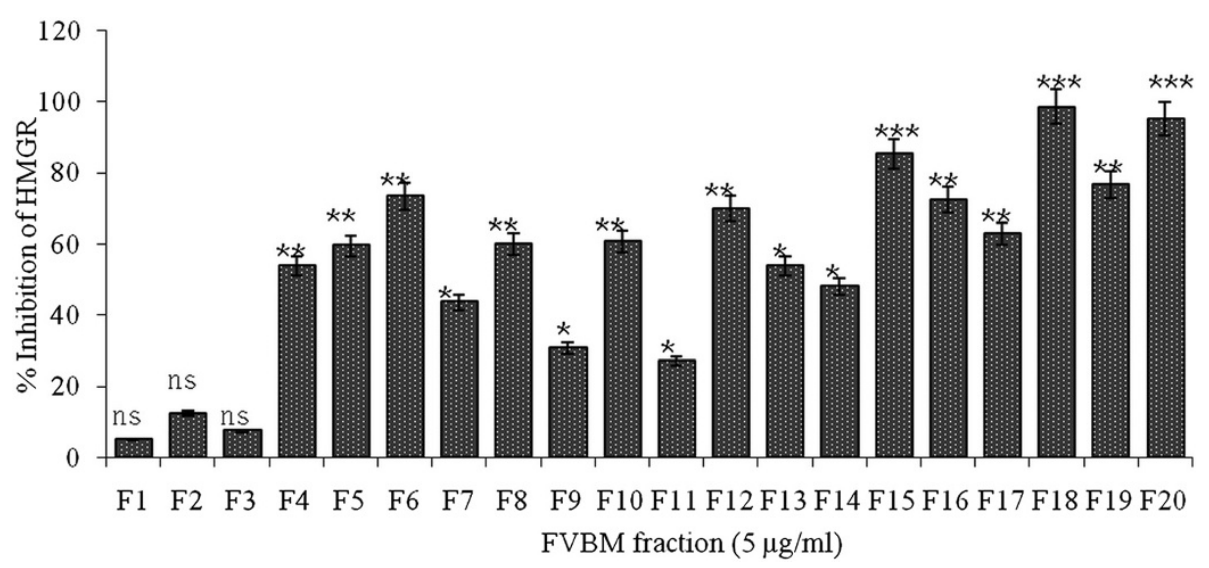

Figure 3 In-vitro HMG-CoA reductase inhibitory activity of FVBM fractions. Values are represented as Mean \pm SD ( $n=3)$. Non-significant (ns), significantly different at ${ }^{*} \mathrm{P}<0.05,{ }^{* *} \mathrm{P}<0.01,{ }^{* * *} \mathrm{P}<0.001 \mathrm{vs} 0 \mu \mathrm{g} / \mathrm{ml}$. 

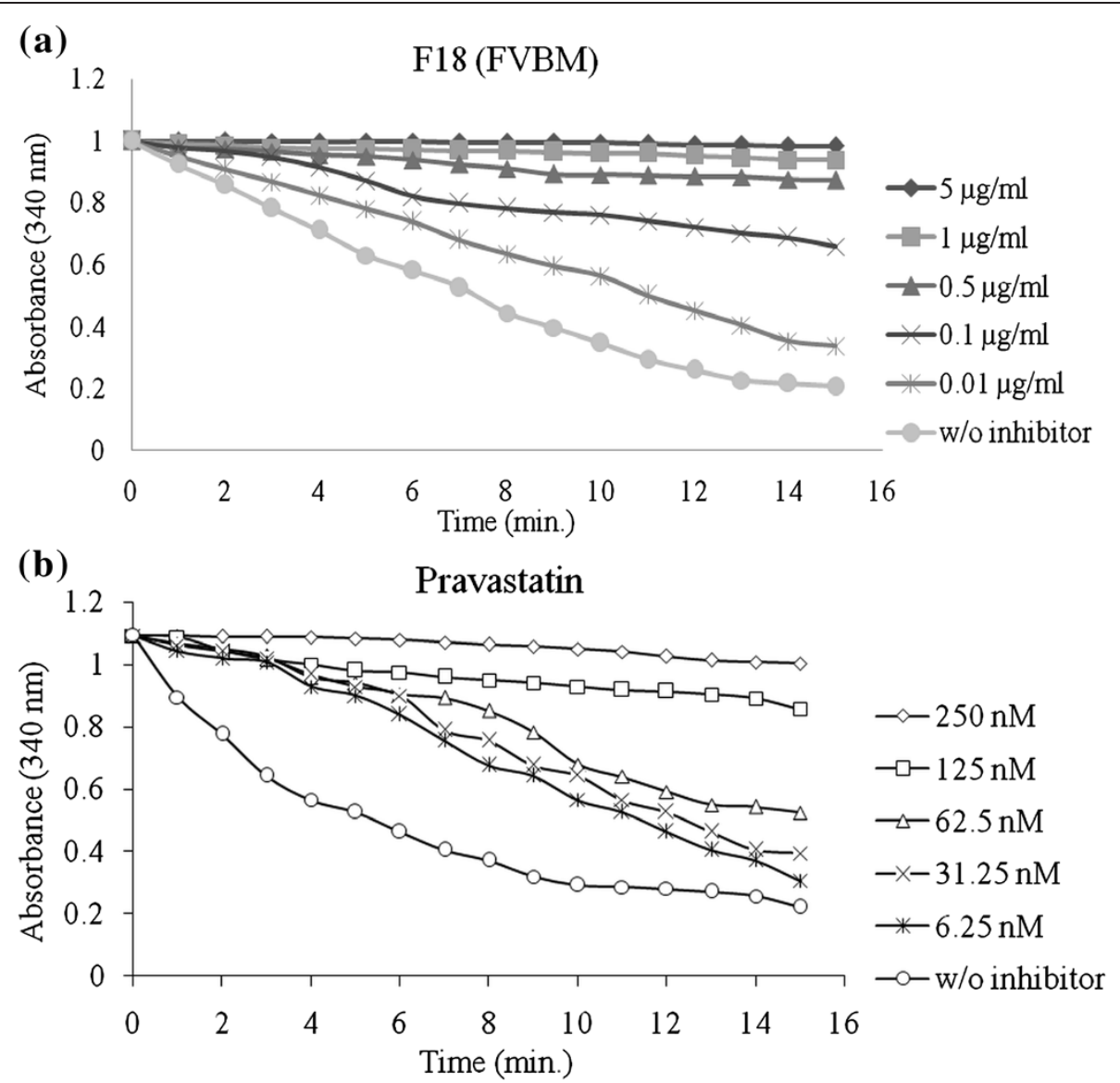

Figure 4 Spectrophotometric time-scans demonstrating the ability of fraction F18 (n-Octadecanyl-O-a-D-glucopyranosyl (6' $\rightarrow$ 1")-0- $\alpha^{\prime}$ D-glucopyranoside) (a) and pravastatin (b) to inhibit HMG-CoA reductase activity.

site, though pravastatin was a more stronger ligand ( $\Delta \mathrm{G}:-6.25 \mathrm{kcal} / \mathrm{mol}$ ) (Figure 7 and Table 3).

\section{ADME predictions}

ADME predictions study of novel compound was done to analyze its pharmacokinetic properties such as aqueous solubility, intestinal absorption, plasma protein binding, blood-brain-barrier penetration, hydrogen bond donor, hydrogen bond acceptor and cytochrome $\mathrm{P}_{450}$ inhibition (Table 4). A comparison between these results and the standard values revealed that this bioactive compound has a good aqueous solubility, undefined blood-brain-barrier penetration, low intestinal absorption, $<90 \%$ plasma protein binding, no inhibition effect on cytochrome P450 and extremely low hepatotoxicity.

\section{LDH release assay}

There was no significant increase in LDH released following incubation of blood platelets with either the test drug F18 or the atorvastatin. $4.3 \%$ of LDH was released in the incubation medium containing hemoglobin and F18. F18 induced weak LDH leakage suggesting that at concentration of $1 \mathrm{mg}$ F18 was not cytotoxic. Moreover, when compared with the standard, at a concentration of $1 \mathrm{mg}$ there is a released of only $3.7 \%$ of $\mathrm{LDH}$ in the incubation medium. Around 4\% LDH leakage is supposed to be weak in cytotoxicity and hence can be said as noncytotoxic at this concentration (Table 5).

\section{In vivo hypolipidemic study}

The efficacy of FVBM extract (50 and $100 \mathrm{mg} / \mathrm{rat}$ ), isolated bioactive compound (1 $\mathrm{mg} / \mathrm{rat}$ ) and standard (Atorvastatin, $1 \mathrm{mg} / \mathrm{rat}$ ) in ameliorating the lipid level was elucidated in Triton WR-1339 induced hyperlipidemic rats after $18 \mathrm{~h}$ of treatment. A significant increase in TG (298\%), TC (377\%) and non HDL-C (592\%) levels in Triton WR-1339 induced hyperlipidemic rats was observed in comparison to NC rats (Table 6). After treatment TG, TC \& non-HDL-C levels were markedly decreased by $74 \%, 77 \%$ and $83 \%$ respectively in the bioactive compound treated group, which was almost comparable to the reduction observed in AT group at the same dose of $1 \mathrm{mg} /$ rat. Furthermore, plasma LDL-C and VLDL-C levels were significantly increased from the 


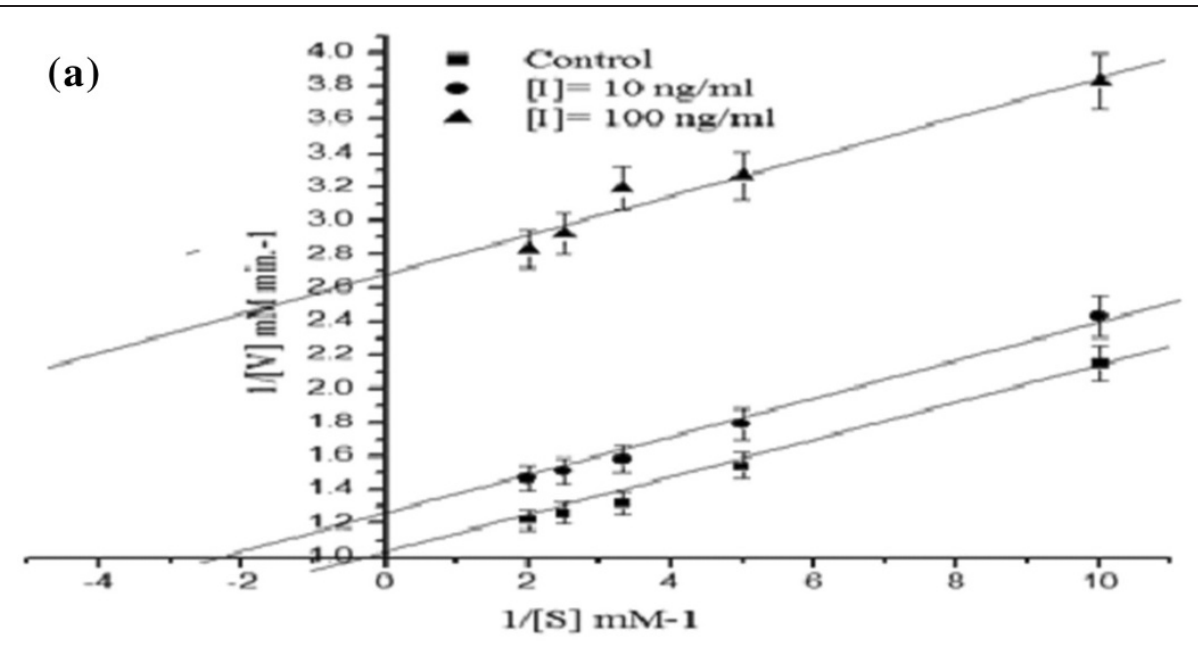

(b)

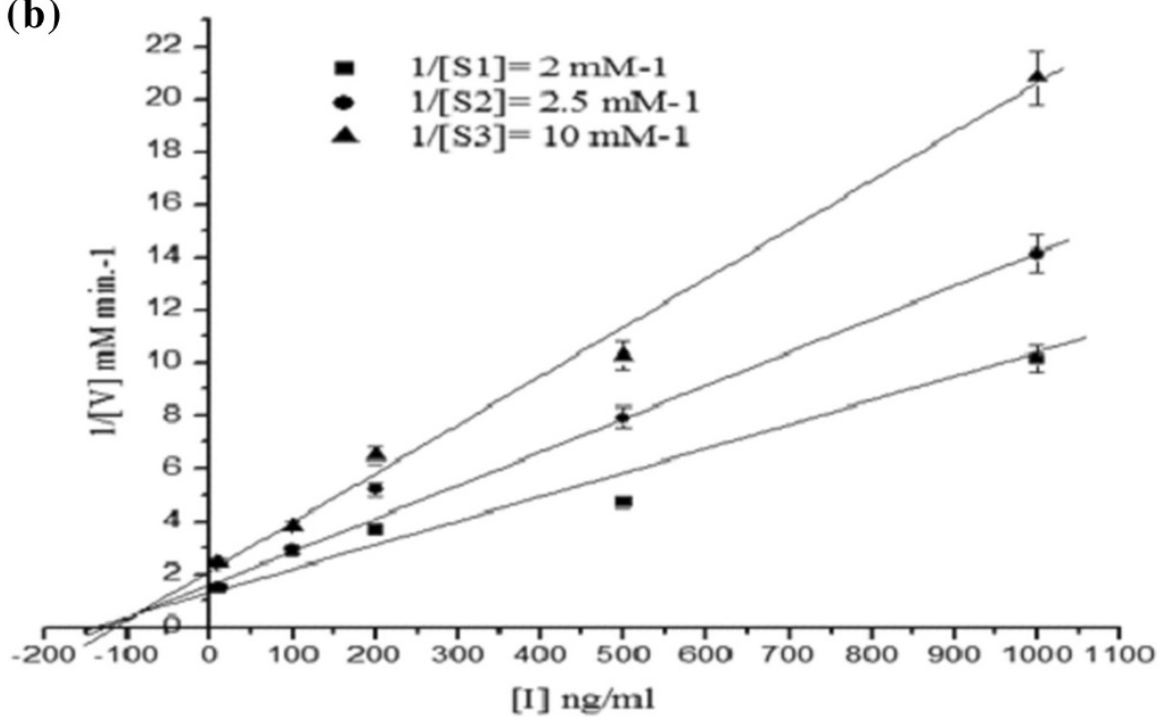

Figure 5 Lineweaver-Burk double reciprocal plot (a) and Dixon plot (b) of fraction F18 (n-Octadecanyl-O-a-D-glucopyranosyl (6' $\rightarrow$ 1")O-a-D-glucopyranoside) against HMG-CoA reductase.

value of $36 \mathrm{mg} / \mathrm{dl}$ and $12 \mathrm{mg} / \mathrm{dl}$ to $280 \mathrm{mg} / \mathrm{dl}$ and $48 \mathrm{mg} / \mathrm{dl}$ respectively in Triton WR-1339 induced hyperlipidemic rats (Table 7). Whereas, the HDL-C value was significantly reduced by $20 \%$ in HLC group, when compared to rats in the control group. After the treatment, a significant decrease of $71 \%$, and $60 \%$ in LDL-C, and $86 \%$ and $71 \%$ in VLDL-C was observed in FVT-1 and FVT-2 groups respectively, when compared to HLC group. Moreover, hyperlipidemic rats treated with bioactive compound (CT) showed marked reduction in LDL-C (85\%) and VLDL-C (74\%) levels, when compared to HLC group, which is almost comparable to the reduction observed in groups treated with high dose of plant extract (FVT-2: $100 \mathrm{mg} / \mathrm{rat}$ ) and atorvastatin (1 mg/rat). In contrast the HDL-C level was significantly increased by $19 \%, 35 \%, 28 \%$ and $29 \%$ in FVT-1, FVT-2, CT and AT groups, when compared to HLC control rats. These results demonstrated that the plant extract at higher dose (FVT-2), the bioactive compound and atorvastatin were almost equally effective in ameliorating plasma lipid levels.

HDL-C/TC, HDL-C/LDL-C, TC/HDL-C and LDL-C/ HDL-C ratios calculated from the data presented in Tables 6 and 7 are shown in Table 8. A significant decrease of 5.89 and 9.74 fold in HDL-C/TC and HDL-C/ LDL-C ratios was observed; whereas, a marked increase in TC/HDL-C and LDL-C/HDL-C ratios was observed in HLC group in contrast to the normal ratios. After the treatment, the decrease in HDL-C/TC and HDL-C/LDL$\mathrm{C}$ ratio was significantly prevented and increased to 


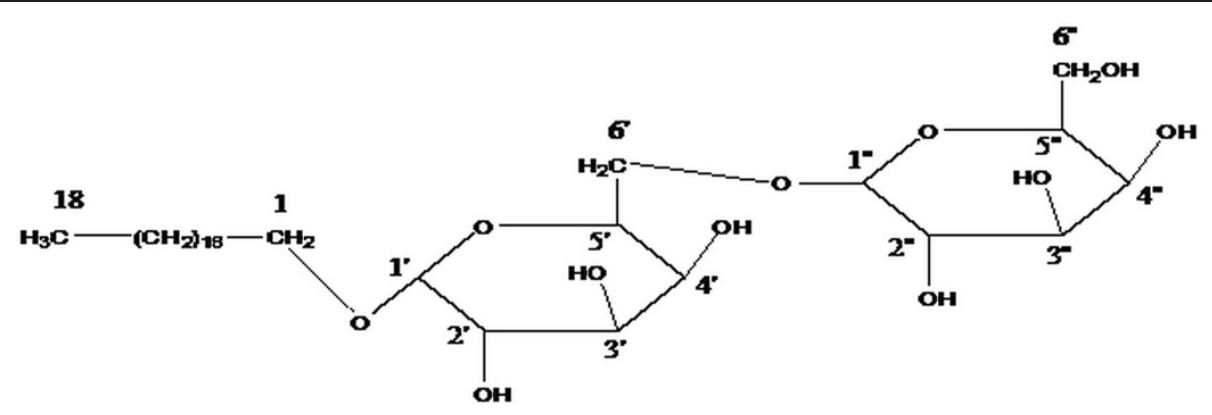

Figure 6 The structure of bioactive fraction F18 (n-Octadecanyl-O-a-D-glucopyranosyl(6' $\rightarrow$ 1")-O-a-D-glucopyranoside).

3.43, 4.13 and 5.73, 9.45 fold, respectively, in FVT-1 and FVT-2 group. Furthermore, atorvastatin and bioactive compound treated rats also exhibited marked increase of 5.42, 8.19 and 5.90, 9.43 fold in HDL-C/TC and HDL-C/ LDL-C ratio. An opposite pattern was observed in TC/ HDL-C and LDL-C/HDL-C ratios. These ratios were significantly increased by 5.88 and 9.73 fold in HLC group, when compared to the normal value of $2.75 \mathrm{mg} / \mathrm{dl}$ and $1.29 \mathrm{mg} / \mathrm{dl}$, respectively. All the treated groups showed a significant reduction in TC/HDL-C and LDL-C/HDL-C ratios when compared to the ratios of HLC group. These results indicated a significant restoration of these ratios close to the normal values, which in turn indicated the normalization of cholesterol level associated with the studied lipoproteins.

The hepatic HMG-CoA reductase activity in Triton WR-1339 induced hyperlipidemic HLC rats was significantly increased by 3.59 fold when compared to NC rats (Table 9). Administration of plant extract in two different doses resulted in a significant decrease in HMGCoA reductase activity by 2.06 and 3.50 fold respectively, when compared to HLC value. It is noteworthy that isolated compound exerted better and significant reduction (3.18 fold) than the atorvastatin (2.18 fold), when compared to HLC control group. These results demonstrated that the decrease in cholesterol level of Triton WR-1339 induced hyperlipidemic rats was due to the decline in enzymatic activity of HMG-CoA reductase activity.

Table 3 Molecular interaction studies of F18 bioactive compound and standards with HMG-CoA reductase

\begin{tabular}{llll}
\hline S. No. & Compound name & $\begin{array}{l}\text { binding } \\
\text { energy } \Delta \mathbf{G} \\
\text { (kcal/mol) }\end{array}$ & Residues involved \\
\hline $1 \quad$ n-Octadecanyl-O-a-D- \\
glucopyranosyl(6' $\left.\rightarrow 1^{\prime \prime}\right)-$ & -5.58 & ASN755, ASP765, \\
O-a-D-glucopyranoside. & & LYS691, GLU559, \\
& & GLY560, ALA525, \\
& & ARG590 \\
& Pravastatin & -6.25 & SER684, LYS735, \\
& & & ARG590, ASP690, \\
& & & GLU560, ASN658 \\
\hline
\end{tabular}

\section{Discussion}

It is well accepted that enzymes are the major regulators of the lipid metabolism; wherein HMG-CoA reductase is one of the most clinically important enzymes involved in the cholesterol biosynthetic pathway. Changes in the reductase activity are closely related to changes in the overall rate of cholesterol synthesis. This suggests that the inhibition of HMG-CoA reductase would be an effective mean to lower plasma cholesterol [44]. Thus, this enzyme is the target of the widely available cholesterollowering drugs known, collectively, as statins [45]. Although, most of the HMG-CoA reductase inhibitors have some adverse side effects $[12,13]$.

In the same vein, oxidative stress also plays a pivotal role in atherosclerosis and subsequent CVD. Therefore, finding an HMG-CoA reductase inhibitor with antioxidant property is of great potential in the treatment and management of hypercholesterolemia and cholesterol induced oxidative stress. The medicinal plants are now being seen as a potent source of the drug discovery program. Epidemiologic studies have shown a correlation between an increased consumption of phenolic antioxidants and a reduced risk of CVD [46-49]. The current interest in combating free radical mediated diseases including atherosclerosis has been shifted toward natural products. The present work was an extension of our recent study in which we screened stem bark and leaf extracts of Ficus virens for an HMG-CoA reductase inhibitory activity. Among all the sequentially extracted fractions, FVBM extract showed most potent antioxidant, genoprotective, and HMG-CoA reductase inhibitory activity ( $\mathrm{IC}_{50}$ value: $3.45 \pm 0.45 \mu \mathrm{g} / \mathrm{ml}$ ) [20]. In the present study, FVBM extract was subjected to a column chromatography in order to identify and isolate the bioactive compounds as well as to examine their antioxidant and HMG-CoA reductase inhibitor property. Moreover, the role of most potent isolated fraction and the FVBM extract was also investigated in Triton WR-1339 induced hyperlipidemic rats. Twenty fractions (F1-F20) of FVBM extract were collected through column chromatography and screened for antioxidant and HMG- 


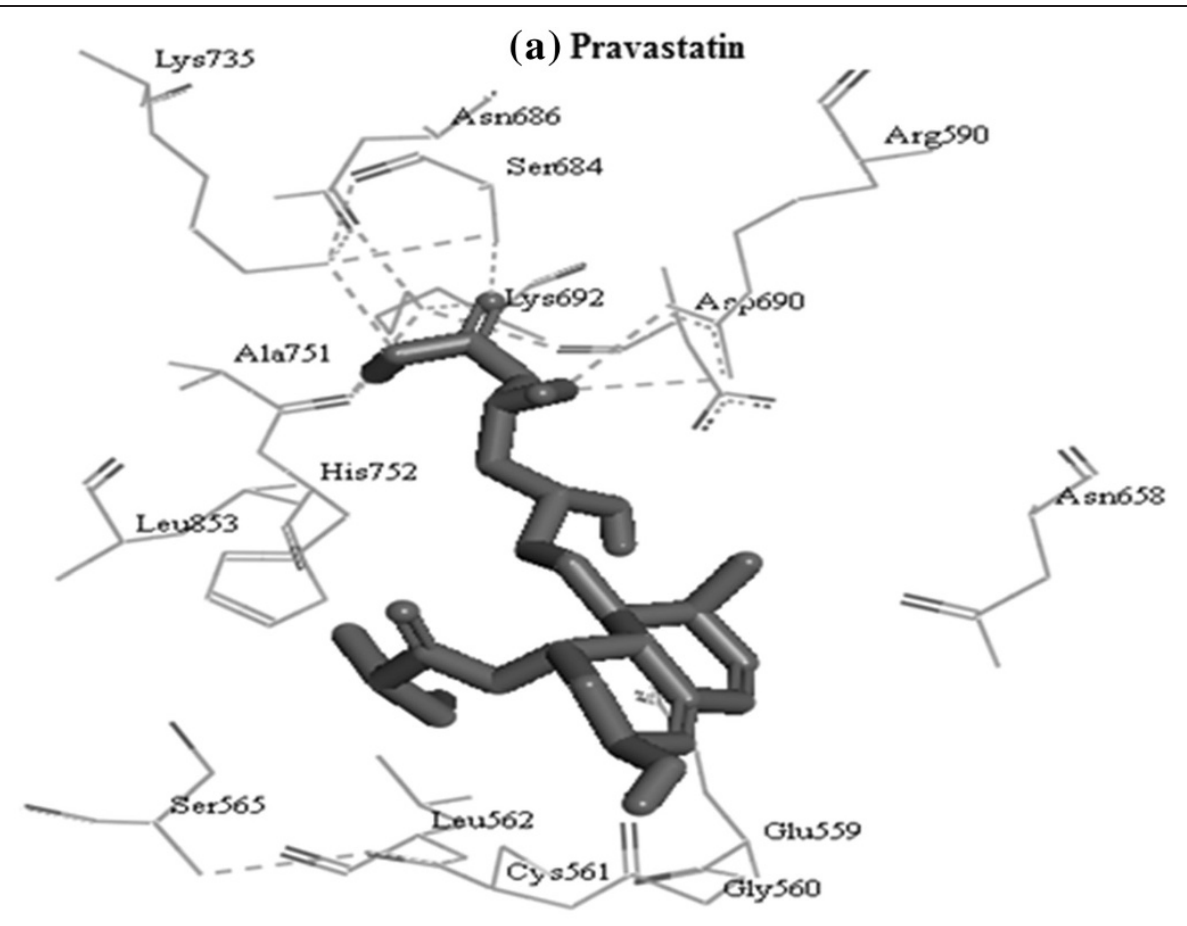

(b) F18 fraction ( n- Octadecanyl-O- $\alpha$-D-glucopyranosyl ( $\left.6^{\prime} \rightarrow 1^{\prime \prime}\right)$-O- $\alpha$-D-glucopyranoside)

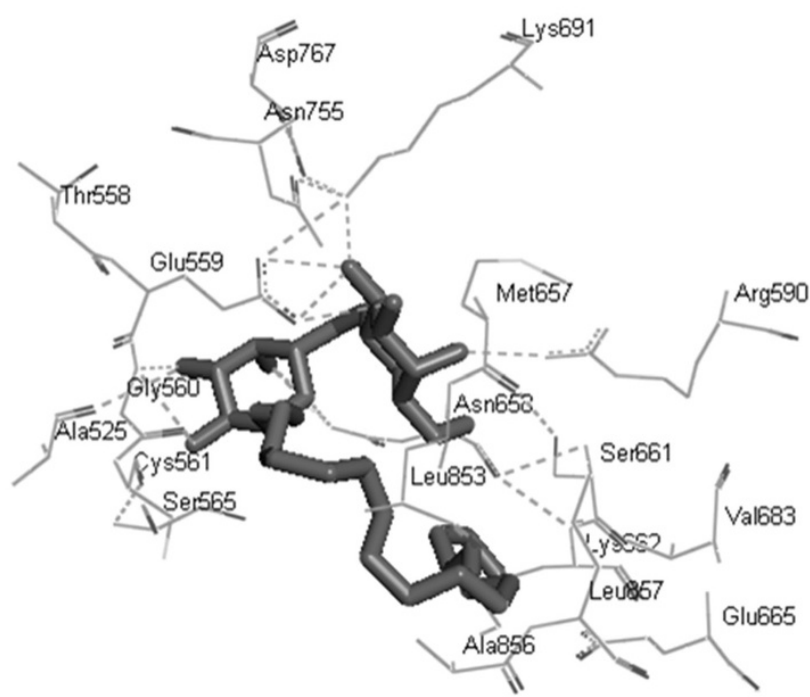

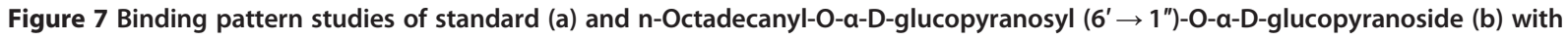
HMG-CoA reductase.

Table 4 Predicted ADME profiles for F18 bioactive compound and standard

\begin{tabular}{llllllllll}
\hline Compound & $\begin{array}{l}\text { Aqueous } \\
\text { Solubility } \\
\text { Intensity }\end{array}$ & $\begin{array}{l}\text { Intestinal } \\
\text { Absorption } \\
\text { Intensity }\end{array}$ & $\begin{array}{l}\text { BBB } \\
\text { Intensity }\end{array}$ & $\begin{array}{l}\text { PPB \% of } \\
\text { binding }\end{array}$ & $\begin{array}{l}\text { CYP450 } \\
\text { Value }\end{array}$ & Hepatotoxicity & A logp 98 & $\begin{array}{l}\text { Hydrogen } \\
\text { bond acceptor }\end{array}$ & $\begin{array}{l}\text { Hydrogen } \\
\text { bond donor }\end{array}$ \\
\hline F18 & 3 & 3 & 4 & 0 & 0 & 0 & 3.863 & 11 & 7 \\
Atorvastatin & 2 & 2 & 4 & 1 & 1 & 1 & 4.701 & 7 & 4 \\
\hline
\end{tabular}


Table 5 Effect of F18, and atorvastatin on total lactate dehydrogenase released in the incubation medium

\begin{tabular}{llll}
\hline Incubation time (Min.) & Control & Atorvastatin (1 $\mathbf{~ g})$ & F18 (1 $\mathbf{~ g g})$ \\
\hline 0 & $0 \pm 0.00$ & $0 \pm 0.000$ & $0 \pm 0.000$ \\
30 & $0.4 \pm 0.30$ & $1.1 \pm 0.25$ & $1.3 \pm 0.23$ \\
60 & $1.1 \pm 0.25$ & $2.0 \pm 0.24$ & $2.2 \pm 0.35$ \\
90 & $1.6 \pm 0.22$ & $3.1 \pm 0.31$ & $3.7 \pm 0.41$ \\
120 & $2.6 \pm 0.24$ & $3.7 \pm 0.36$ & $4.3 \pm 0.37$ \\
\hline
\end{tabular}

Results are presented as mean \pm SD.

CoA reductase inhibitory activities. DPPH and FRAP methods are frequently used for screening the antioxidant potency of plants [21-23]. DPPH is a stable free radical commonly used to evaluate free radical scavenging activity of antioxidants. The fraction F18 exhibited higher radical scavenging activity of $51 \%$ at $5 \mu \mathrm{g} / \mathrm{ml}$ than the other fractions and standard ascorbic acid $(12.7 \%$ at $5 \mu \mathrm{g} / \mathrm{ml})$. The ability of this fraction to reduce ferric ions to ferrous ions, generally used to determine the antioxidant power, was also evaluated and it showed significantly higher antioxidant capacity in comparison to other fractions similar to earlier reports [18-20]. As discussed, HMG-CoA reductase is a major regulatory enzyme of cholesterol biosynthetic pathway; and majority of lipid lowering drugs work by inhibiting the activity of this enzyme. Employing a previously standardized protocol [20,43], a marked HMG-CoA reductase inhibitory activity with an $\mathrm{IC}_{50}$ value of $84 \pm 2.8 \mathrm{ng} / \mathrm{ml}$ was observed in fraction F18. Here it is interesting to mention that F18

Table 6 Effect of FVBM extract, F18 bioactive compound and atorvastatin on plasma triglycerides, total cholesterol and non-HDL-cholesterol in Triton WR-1339 induced hyperlipidemic rats after 18 hours of treatment

\begin{tabular}{llll}
\hline Group & Triglycerides & Total cholesterol & Non-HDL-cholesterol \\
\hline NC & $60.45 \pm 1.22^{*}$ & $75.86 \pm 1.32$ & $47.5 \pm 1.17$ \\
HLC & $240.74 \pm 3.36^{*}$ & $361.92 \pm 4.86$ & $328.38 \pm 3.6$ \\
& $(+298.24 \%)^{\mathrm{a}}$ & $(+377.08 \%)^{\mathrm{a}}$ & $(+591.32 \%)^{\mathrm{a}}$ \\
FVT-1 & $95.47 \pm 2.69^{*}$ & $126.17 \pm 2.8$ & $100.24 \pm 2.5$ \\
& $(-60.34 \%)^{\mathrm{a}}$ & $(-65.13 \%)^{\mathrm{a}}$ & $(-69.47 \%)^{\mathrm{a}}$ \\
FVT-2 & $65.42 \pm 1.17^{*}$ & $84.25 \pm 1.25$ & $53.3 \pm 1.19$ \\
& $(-72.82 \%)^{\mathrm{a}}$ & $(-76.79 \%)^{\mathrm{a}}$ & $(-83.76 \%)^{\mathrm{a}}$ \\
CT & $62.7 \pm 1.48^{*}$ & $84.5 \pm 2.25$ & $55.8 \pm 1.12$ \\
& $(-73.95 \%)^{\mathrm{a}}$ & $(-76.65 \%)^{\mathrm{a}}$ & $(-83.00 \%)^{\mathrm{a}}$ \\
AT & $58.6 \pm 1.15^{*}$ & $78.23 \pm 1.25$ & $49.6 \pm 1.18$ \\
& $(-75.65 \%)^{\mathrm{a}}$ & $(-78.38 \%)^{\mathrm{a}}$ & $(-81.85 \%)^{\mathrm{a}}$ \\
\hline
\end{tabular}

${ }^{\dagger}$ For the calculation of non-HDL-C, data is taken from Tables 5 and 6. *Values are mean $(\mathrm{mg} / \mathrm{dl}) \pm \mathrm{SD}$ from plasma of 5 rats in each group. $\mathrm{NC}$, normal control; HLC, triton induced hyperlipidemic control; FVT-1, fed 50 mg FVBM extract/ rat; FVT-2, fed 100 mg FVBM extract/ rat; CT, fed 1 mg F18 bioactive compound/ rat and AT, given $1 \mathrm{mg}$ atorvastatin/rat once. Significantly different from NC at ${ }^{a} \mathrm{p}<0.001$.

Significantly different from $\mathrm{HLC}$ at ${ }^{\mathrm{a}} \mathrm{p}<0.001$.
Table 7 Effect of FVBM, F18 bioactive compound and atorvastatin on plasma LDL-C, HDL-C and VLDL-C in Triton WR-1339 induced hyperlipidemic rats after 18 hours of treatment

\begin{tabular}{llll}
\hline Group & LDL-C & HDL-C & VLDL-C \\
\hline NC & $35.5 \pm 1.12^{*}$ & $27.5 \pm 0.99$ & $12 \pm 0.67$ \\
HLC & $280.12 \pm 4.36^{*}$ & $22.28 \pm 0.56$ & $48.26 \pm 1.45$ \\
& $(+646.66 \%)^{a}$ & $(-20 \%)^{a}$ & $(+300.04 \%)^{a}$ \\
FVT-1 & $81.15 \pm 2.19^{*}$ & $26.63 \pm 0.74$ & $19.09 \pm 0.81$ \\
& $(-71.07 \%)^{a}$ & $(+19.3 \%)^{a}$ & $(-60.41 \%)^{a}$ \\
FVT-2 & $39.5 \pm 1.37^{*}$ & $29.7 \pm 1.15$ & $13.08 \pm 0.64$ \\
& $(-85.89 \%)^{a}$ & $(+35 \%)^{a}$ & $(-71.40 \%)^{a}$ \\
CT & $43.26 \pm 1.25^{*}$ & $28.2 \pm 1.14$ & $12.54 \pm 0.63$ \\
& $(-84.55 \%)^{a}$ & $(+28.18 \%)^{a}$ & $(-74.01 \%)^{a}$ \\
AT & $37.88 \pm 1.18^{*}$ & $28.4 \pm 1.15$ & $11.72 \pm 0.52$ \\
& $(-86.47 \%)^{a}$ & $(+29.09 \%)^{a}$ & $(-75.71 \%)^{a}$ \\
\hline
\end{tabular}

*Values are mean $(\mathrm{mg} / \mathrm{dl}) \pm$ SD from LDL-C, HDL-C and VLDL-C, isolated from plasma of 5 rats in each group.

NC, normal control; HLC, triton induced hyperlipidemic control; FVT-1, fed 50 mg FVBM extract/rat; FVT-2, fed 100 mg FVBM extract/rat; CT, fed 1 mg F18 bioactive compound/rat and AT, given $1 \mathrm{mg}$ atorvastatin/rat once.

Significantly different from NC at ${ }^{a} p<0.001$.

Significantly different from HLC at ${ }^{\mathrm{a}} \mathrm{p}<0.001$.

fraction exhibited better $\mathrm{IC}_{50}$ value than that of FVBM crude extract [20]. To the best of our knowledge and on the basis of literature review, the demonstrated HMGCoA reductase inhibitory activity was significantly better than the reported inhibitors from various plants like kiwifruit [50], Quercus infectoria, Rosa damascene and Myrtus communis [51], indicating its potent hypolipidemic property. The fraction F18 was identified as Octadecanyl-O- $\alpha-$ D-glucopyranosyl (6' $\left.\rightarrow 1^{\prime \prime}\right)$-O- $\alpha$-D-glucopyranoside. This is a new and completely different structure than the other inhibitors isolated from various plants such as tocotrienol from barley [52], kakkalide and irisolidone from flower of Pueraria thunbergiana [53], camphene, a plant-Derived monoterpene [54], daidzein from Pueraria thunbergiana [55], acetylenic acids from the root bark of Paramacrolobium caeruleum [56], and flavonoids from the buds of Rosa damascena [57].

Furthermore, to understand the binding mechanism and corroborate our in vitro hypothesis, in silico molecular interaction studies were conducted between HMG-CoA reductase and the inhibitor F18. The docked structure of F18-HMG-CoA reductase involved contributions from

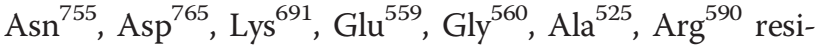
dues, which were not from the catalytic domain of the enzyme. This confirms the uncompetitive mode of inhibition observed in vitro.

The result of interaction study of standard drug pravastatin with HMG-CoA reductase is in consensus with our previously published data $[20,43,58]$. In addition, this novel F18 compound showed good aqueous solubility, 
Table 8 Effect of FVBM, F18 bioactive compound and atorvastatin on the ratios of plasma HDL-C/TC, HDL-C/LDL-C, TC/HDL-C and LDL-C/HDL-C in Triton WR-1339 induced hyperlipidemic rats after 18 hours of the treatment

\begin{tabular}{|c|c|c|c|c|}
\hline Group/Ratio $^{\dagger}$ & HDL-C/TC & HDL-C/LDL-C & TC/HDL-C & LDL-C/ HDL-C \\
\hline NC & $0.3625 \pm .025^{*}$ & $0.7746 \pm 0.088$ & $2.758 \pm 0.105$ & $1.2909 \pm 0.0576$ \\
\hline \multirow[t]{2}{*}{ HLC } & $0.0615 \pm 0.003^{*}$ & $0.0795 \pm 0.0074$ & $16.244 \pm 0.76$ & $12.5727 \pm 0.65$ \\
\hline & $(-5.89 f)^{a}$ & $(-9.74 f)^{a}$ & $(+5.88 f)^{a}$ & $(+9.73 f)^{a}$ \\
\hline \multirow[t]{2}{*}{ FVT-1 } & $0.2110 \pm 0.0048^{*}$ & $0.3281 \pm 0.0075$ & $4.737 \pm 0.094$ & $3.0473 \pm 0.086$ \\
\hline & $(+3.43 f)^{a}$ & $(+4.13 f)^{a}$ & $(-3.43 f)^{a}$ & $(-4.12 f)^{a}$ \\
\hline \multirow[t]{2}{*}{ FVT-2 } & $0.3525 \pm 0.0071^{*}$ & $0.7518 \pm 0.074$ & $2.836 \pm 0.115$ & $1.3299 \pm 0.034$ \\
\hline & $(+5.73 f)^{a}$ & $(+9.45 f)^{a}$ & $(-5.72 f)^{a}$ & $(-9.45 f)^{a}$ \\
\hline \multirow[t]{2}{*}{ CT } & $0.3337 \pm 0.0042^{*}$ & $0.6518 \pm 0.015$ & $2.996 \pm 0.081$ & $1.5340 \pm 0.0691$ \\
\hline & $(+5.42 \mathrm{f})^{\mathrm{a}}$ & $(+8.19 f)^{a}$ & $(-5.42 f)^{a}$ & $(-8.21 \mathrm{f})^{\mathrm{a}}$ \\
\hline \multirow[t]{2}{*}{ AT } & $0.3630 \pm 0.0036^{*}$ & $0.7497 \pm 0.028$ & $2.754 \pm 0.129$ & $1.3338 \pm 0.064$ \\
\hline & $(+5.90 f)^{a}$ & $(+9.43 f)^{a}$ & $(-5.89 f)^{a}$ & $(-9.42 f)^{a}$ \\
\hline
\end{tabular}

${ }^{\dagger}$ For the calculation of ratios, data is taken from Tables 5 and 6.

*Values are mean $(\mathrm{mg} / \mathrm{dl}) \pm$ SD from plasma of 5 rats in each group.

NC, normal control; HLC, triton induced hyperlipidemic control; FVT-1, fed 50 mg FVBM extract/rat; FVT-2, fed 100 mg FVBM extract/rat; CT, fed 1 mg F18 bioactive compound/rat and AT, given $1 \mathrm{mg}$ atorvastatin/rat once.

' $f$ ' stands for fold.

Significantly different from NC at ${ }^{a} p<0.001$

Significantly different from HLC at ${ }^{a} \mathrm{p}<0.001$.

low blood-brain-barrier penetration, low intestinal absorption, $<90 \%$ plasma protein binding, no inhibition effect on cytochrome $\mathrm{P}_{450}$ and extremely low hepatotoxicity, indicating it to be safe as a potential drug. In addition, the novel compound also showed weak LDH release which indicates that it is non cytotoxic at concentration of $1 \mathrm{mg}$.

Table 9 Effect of FVBM, F18 bioactive compound and atorvastatin on in vivo modulation of hepatic HMG-CoA reductase activity in Triton WR-1339 induced hyperlipidemic rats after 18 hours of the treatment

\begin{tabular}{ll}
\hline Group & HMG-CoA reductase activity \\
\hline NC & $4.35 \pm 0.22^{*}$ \\
HLC & $1.21 \pm 0.041^{*}$ \\
& $(+3.59 \mathrm{f})^{\mathrm{a}}$ \\
FVT-1 & $2.499 \pm 0.057^{*}$ \\
& $(-2.06 \mathrm{f})^{\mathrm{a}}$ \\
FVT-2 & $4.24 \pm 0.15^{*}$ \\
& $(-3.50 \mathrm{f})^{\mathrm{a}}$ \\
CT & $3.85 \pm 0.13^{*}$ \\
& $(-3.18 \mathrm{f})^{\mathrm{a}}$ \\
AT & $2.64 \pm 0.075^{*}$ \\
& $(-2.18 \mathrm{f})^{\mathrm{a}}$ \\
\hline
\end{tabular}

${ }^{\dagger}$ Expressed as ratio of HMG-CoA to Mevelonate; lower the ratio higher the enzyme activity.

*Values are mean \pm SD from liver homogenate of 5 rats in each group. NC, normal control; HLC, triton induced hyperlipidemic control; FVT-1, fed 50 mg FVBM extract/rat; FVT-2, fed 100 mg FVBM extract/rat; CT, fed 1 mg F18 bioactive compound/rat and AT, given $1 \mathrm{mg}$ atorvastatin/rat for once. Significantly different from NC at ${ }^{a} p<0.001$.

Significantly different from $\mathrm{HLC}$ at ${ }^{\mathrm{a}} \mathrm{p}<0.001$.
Based on the above in vitro and in silico rationale, in vivo study was designed to evaluate the hypolipidemic properties of FVBM extract, bioactive compound and standard drug atorvastatin in the triton-induced hyperlipidemic rat model. The triton-induced hyperlipidemic rat model has been successfully employed to evaluate antidyslipidemic activity $[59,60]$. Triton WR-1339 is a non-ionic surfactant, which elevates the plasma lipids on administration, causes changes in circulatory lipoproteins, suppresses lipoprotein lipase (LPL) activity, hinders the uptake of circulating lipids by extra hepatic tissues, and increases the HMG-CoA reductase activity resulting in increased blood lipid concentrations, hence hyperlipidemia. The present study demonstrated a significant increase in TG, TC, VLDL-C and LDL-C levels with a decrease in HDL-C value in triton-induced hyperlipidemic rats, which was in agreement with previously published data [61]. This increase in plasma TG and TC by triton was due to increase in HMG-CoA reductase activity and by inhibition of lipoprotein lipase responsible for hydrolysis of plasma lipids $[60,62]$. FVBM extract at higher dose $(100 \mathrm{mg} / \mathrm{rat})$ and F18 compound effectively blocked the increase in TG, TC, LDL-C and non-HDL-C levels and reversed them to normal values; thus showed a comparable effect with atorvastatin. Moreover, the HDL-C level was also significantly increased after treatment with the plant extract and F18 compound which in turn offered better protection to LDL as well as HDL from oxidative stress through its associated antioxidant enzyme paraoxonase (PON) [63,64].

It has been established that LDL-C/HDL-C and HDL-C/ $\mathrm{TC}$ ratios are good predictors of presence and severity of CAD [65]. We observed a significant decrease in HDL-C/ 
LDL-C and HDL-C/TC ratio and increase in TC/HDL-C and LDL-C/HDL-C ratios in hyperlipidemic control rats. The ratios related to TC, LDL-C and HDL-C in FVT-2 \& F18 treated groups were positively modulated and restored similar to corresponding ratio values in NC. These results indicate that therapeutic amelioration in plasma TC by F18 or FVBM could be attributed to the changes mainly in LDL$C$ levels, which emphasize the usefulness of these agents in decreasing cardiovascular morbidity and mortality [66].

The significant increase in plasma and lipoprotein lipid levels in triton induced hyperlipidemic rats is consistent with the increase in hepatic HMG-CoA reductase activity. Earlier studies have demonstrated that intravenous or intraperitoneal injection of Triton WR-1339 increases hepatic cholesterol synthesis by increasing HMG-CoA reductase activity, the rate limiting enzyme in the cholesterol biosynthetic pathway in rodents $[67,68]$. Treatment of hyperlipidemic rats with FVBM extract (at higher dose) and fraction F18 significantly alleviated the increased lipid levels and restored them close to the normal values, it may provide a mechanism of reduction of plasma cholesterol level in triton induced hyperlipidemic rat model. Our results are in concordance with earlier reports demonstrating that the reduction in HMG-CoA reductase activity is responsible for the hypolipidemic property of natural agents $[53,58,69]$. This lipid lowering activity might be due to the pleiotropic effect that the compound exhibits through reduced HMG-CoA reductase activity, with significant antioxidant property and increased lipoprotein lipase activity. The compound F18 showed, at an equivalent dose of drug atorvastatin, marked hypolipidemic property and might be a drug candidate.

\section{Conclusion}

In conclusion, our in vitro, in silico and in vivo results clearly demonstrated the therapeutic efficacy of novel HMG-CoA reductase inhibitor (F18-n-Octadecanyl-O- $\alpha-$ D-glucopyranosyl(6' $\left.\rightarrow 1^{\prime \prime}\right)$-O- $\alpha$-D-glucopyranoside) over statins as a substitute against hyperlipidemia. Moreover, being a natural agent with potent antioxidant and hypolipidemic property, this compound could be used in the protection of $\mathrm{ROS} /$ free radical-induced oxidative damage, hyperlipidemia/dyslipidemia and atherosclerotic complications. However, further large scale preclinical and clinical trials are needed to set up its lipid lowering and antiatherosclerotic properties.

\section{Additional files}

Additional file 1: Figure S1. ${ }^{1} \mathrm{H}$ NMR data of fraction F18.

Additional file 2: Figure S2. ${ }^{13} \mathrm{C}$ NMR data of fraction F18.

Additional file 3: Figure S3. IR data of fraction F18.

Additional file 4: Figure S4. Mass spectroscopy data of fraction F18.

\section{Competing interests}

The authors declare that they have no competing interests.

\section{Authors' contributions}

MSK and DI conceived and designed the experiments; DI and MSH performed the experiments; MSK, M. Sajid Khan, SA, and MA analyzed the data; DI, MSK, and SA wrote the paper. All authors read and agreed to the final version of the manuscript.

\section{Acknowledgement}

We thank SAIF facility of Central Drug Research Laboratory, Lucknow, India, for performing the IR, NMR \& Mass spectroscopy. The infrastructure support from institution (IU) is gratefully acknowledged.

\section{Author details}

${ }^{1}$ Department of Biosciences, Clinical Biochemistry \& Natural Product Research Lab, Integral University, Lucknow 226026, India. ${ }^{2}$ Department of Pharmacy, Integral University, Lucknow 226026, India. ${ }^{3}$ Department of Pharmacognosy \& Phytochemistry, Faculty of Pharmacy, Jamia Hamdard, New Delhi 110062, India.

Received: 19 December 2014 Accepted: 13 February 2015

Published online: 04 March 2015

\section{References}

1. Leeder S, Raymond S, Greenberg H, Liu H, Esson K. A race against time: the challenge of cardiovascular disease in developing countries. New York: Trustees of Columbia University; 2004.

2. Guilbert JJ. The world health report 2002-reducing risks, promoting healthy life. Educ Health (Abingdon). 2003;16:230.

3. Stocker R, Keaney Jr JF. Role of oxidative modifications in atherosclerosis. Physiol Rev. 2004;84:1381-478.

4. Whitman SC, Sawyez CG, Miller DB, Wolfe BM, Huff MW. Oxidized type IV hypertriglyceridemic VLDL-remnants cause greater macrophage cholesteryl ester accumulation than oxidized LDL. J Lipid Res. 1998:39:1008-20.

5. Steinberg D. Atherogenesis in perspective: hypercholesterolemia and inflammation as partners in crime. Nat Med. 2002:8:1211-7.

6. Brown MS, Goldstein JL. Multivalent feedback regulation of HMG CoA reductase, a control mechanism coordinating isoprenoid synthesis and cell growth. J Lipid Res. 1980;21:505-17.

7. Carbonell T, Freire E. Binding thermodynamics of statins to HMG-COA reductase. Biochemistry. 2005;44:11741-8.

8. Corsini A, Maggi FM, Catapano AL. Pharmacology of competitive inhibitors of HMG-CoA reductase. Pharmacol Res. 1995;31:9-27.

9. Baigent C, Keech A, Kearney PM, Blackwell L, Buck G, Pollicino C, et al. Efficacy and safety of cholesterol-lowering treatment: prospective meta-analysis of data from 90,056 participants in 14 randomized trials of statins. Lancet. 2005;366(9493):1267-78.

10. Jones PH, Bays HE, Davidson MH, Kelly MT, Buttler SM, Setze CM, et al. Evaluation of a new formulation of fenofibric acid, ABT-335, co-administered with statins: study design and rationale of a phase III clinical programme. Clin Drug Investig. 2008;28:625-34.

11. Oorni K, Posio P, Ala-Korpela M, Jauhiainen M, Kovanen PT. Sphingomyelinase induces aggregation and fusion of small very low-density lipoprotein and intermediate-density lipoprotein particles and increases their retention to human arterial proteoglycans. Arterioscler Thromb Vasc Biol. 2005;25:1678-83.

12. Alsheikh-Ali AA, Karas RH. Adverse events with concomitant amiodarone and statin therapy. Prev Cardiol. 2005;8:95-7.

13. Joy TR, Hegele RA. Narrative review: statin-related myopathy. Ann Intern Med. 2009;150(12):858-68.

14. Reyes-Soffer G, Ngai Cl, Lovato L, Karmally W, Ramakrishnan R, Holleran S, et al. Effect of combination therapy with fenofibrate and simvastatin on postprandial lipemia in the ACCORD lipid trial. Diabetes Care. 2013;36:422-8.

15. Endo A, Kuroda M, Tsujita Y. ML-236A, ML-236B, and ML-236C, new inhibitors of cholesterogenesis produced by Penicillium citrinum. J Antibiot (Japan). 1976;29:1346-8.

16. Endo A. The discovery and development of HMG-CoA reductase inhibitors. J Lipid Res. 1992:33:1569-82.

17. Anandjiwala S, Bagul MS, Parabia M, Rajani M. Evaluation of free radical scavenging activity of an Ayurvedic formulation Panchvalakala. Indian J Pharm Sci. 2008;70:31-5. 
18. Shi YX, Xu YK, Hu HB, Na Z, Wang WH. Preliminary assessment of antioxidant activity of young edible leaves of seven Ficus species in the ethnic diet in Xishuangbanna, Southwest China. Food Chem. 2011;128:889-94.

19. Hameed ESSA. Total phenolic contents and free radical scavenging activity of certain Egyptian Ficus species leaf samples. Food Chem. 2009;114:1271-7.

20. lqbal D, Khan MS, Khan MS, Ahmad S, Srivastava AK. An in vitro and molecular informatics study to evaluate the antioxidative and $\beta$-hydroxy- $\beta$ methylglutaryl-CoA reductase inhibitory property of Ficus virens Ait. Phytother Res. 2013. doi:10.1002/ptr.5077.

21. Williams BW, Cuvelier ME, Berset C. Use of free radical method to evaluate antioxidant activity. LWT. 1995;28:25-30.

22. Benzie IFF, Strain JJ. The ferric reducing ability of plasma (FRAP) as a measure of "antioxidant power": the FRAP assay. Anal Biochem. 1996;239:70-6.

23. Wong CC, Li HB, Cheng KW, Chen FA. Systematic survey of antioxidant activity of 30 Chinese medicinal plants using the ferric reducing antioxidant power assay. Food Chem. 2006;97:705-11.

24. Lineweaver $\mathrm{H}$, Burk $\mathrm{D}$. The determination of enzyme dissociation constants. J Amer Chem Soc. 1934;56:658.

25. Dixon M. The determination of enzyme inhibitor constants. Biochem J. 1953;55:170-1.

26. Goodsell DS, Morris GM, Olson AJ. Automated docking of flexible ligands: applications of AutoDock. J Mol Recognit. 1996;9:1-5.

27. Huey R, Morris GM, Olson AJ, Goodsell DSA. Semiempirical free energy force field with charge based desolvation. J Comput Chem. 2007;28:1145-52.

28. Cheng A, Merz KM. Prediction of aqueous solubility of a diverse set of compounds using quantitative structure property relationships. J Med Chem. 2003;46:3572-80.

29. Kelder J, Grootenhuis PD, Bayada DM, Delbressine LP, Ploemen JP. Polar molecular surface as a dominating determinant for oral absorption and brain penetration of drugs. Pharm Res. 1999;16:1514-9.

30. Colmenarejo G, Alvarez-Pedraglio A, Lavandera JL. Cheminformatic models to predict binding affinities to human serum albumin. J Med Chem. 2001;44:4370-8.

31. Egan WJ, Merz KMJR, Baldwin J. Prediction of drug absorption using multivariate statistics. J Med Chem. 2000;43:3867-77.

32. Susnow RG, Dixon SL. Use of robust classification techniques for of human cytochrome P450 2D6 inhibition. J Chem Inform Comp Sci. 2003;43:1308-15.

33. Hafeez A, Jain U, Sajwan P, Srivastava S, Thakur A. Evaluation of Carrageenan induced anti-inflammatory activity of ethanolic extract of bark of Ficus virens Linn. in swiss albino mice. J Phytopharmacol. 2013;2:39-43.

34. Jayashree P, Shridhar NB, Vijaykumar M, Suhasini KJ, Satyanarayana ML. Toxicological studies of Ficus Virens in Wistar Albino Rats. Int Res J Pharmacy. 2012;3:84-7.

35. Harnafi H, El-Houda-Bouanani N, Aziz M, Caid HS, Ghalim N, Amrani S. The hypolipidaemic activity of aqueous Erica multiflora flowers extract in Triton WR-1339 induced hyperlipidaemic rats: a comparision with fenofibrate. J Ethnopharmacol. 2007;109:156-60.

36. Kumar V, Khan MM, Khanna AK, Singh R, Singh S, Chander R, et al. Lipid lowering activity of Anthocephalus indicus root in hyperlipidemic rats. Evid Based Complement Alternat Med. 2010;7:317-22.

37. Wieland H, Seidel D. A simple specific method for precipitation of low density lipoproteins. J Lipid Res. 1983;24:904-9.

38. Patsch W, Brown SA, Morrisett JD, AM G (J), Patsch JR. A dual-precipitation method evaluated for measurement of cholesterol in high-density lipoprotein sub fractions $\mathrm{HDL}_{2}$ and $\mathrm{HDL}_{3}$ in human plasma. Clin Chem. 1989:35:265-70

39. Trinder P. Quantitative determination of triglyceride using GPO-PAP method. Ann Biochem. 1969;6:24-7.

40. Friedewald WT, Levy RI, Fredrickson DS. Estimation of the concentration of low-density lipoprotein cholesterol in plasma, without use of the preparative ultracentrifuge. Clin Chem. 1972;18:499-502.

41. Rao V, Ramakrishnan A. Indirect assessment of hydroxyl methyl gultaryl CoA reductase (NAOPH) activity in liver tissue. Clin Chem. 1975;21:1523-5.

42. Ahmad S, Shahab U, Baig MH, Khan MS, Khan MS, Srivastava AK, et al. Inhibitory effect of metformin and pyridoxamine in the formation of early, intermediate and advanced glycation end-products. PLoS One. 2013;8(9):e72128.

43. Iqbal D, Khan MS, Khan A, Khan MS, Ahmad S, Srivastava AK, et al. In vitro screening for $\beta$-hydroxy- $\beta$-methylglutaryl-coa reductase inhibitory and antioxidant activity of sequentially extracted fractions of Ficus palmata Forsk. BioMed Res Int. 2014;Article ID 762620:1-10. http://dx.doi.org/10.1155/ 2014/762620.
44. Visavadiya NP, Narasimhacharya AVRL. Asparagus root regulates cholesterol metabolism and improves antioxidant status in hypercholesteremic rats. Advance Access Publication. 2009;6:219-26.

45. Da Silva VB, Taft CA, Silva CHTP. Use of virtual screening, flexible docking, and molecular interaction fields to design novel $\mathrm{HMG}-\mathrm{Co}$ A reductase inhibitors for the treatment of hypercholesterolemia. J Phys Chem A. 2008;112:2007-11.

46. Naruszewicz M, Laniewska I, Millo B, Dluzniewski M. Combination therapy of statin with flavonoids rich extract from chokeberry fruits enhanced reduction in cardiovascular risk markers in patients after myocardial infarction (MI). Atherosclerosis. 2007;194:e179-84. doi:10.1016/j. atherosclerosis.2006.12.032.

47. George TW, Niwat C, Waroonphan S, Gordon MH, Lovegrove JA. Effects of chronic and acute consumption of fruit-and vegetable-puree-based drinks on vasodilation, risk factors for CVD and the response as a result of the eNOS G298T polymorphism. Proc Nutr Soc. 2009;68:148-61.

48. Clifton PM. Effect of grape seed extract and quercetin on cardiovascular and endothelial parameters in high-risk subjects. J Biomed Biotechnol. 2004:5:272-8.

49. Shahidi F, Janitha PK, Wanasundara PD. Phenolic antioxidants. Crit Rev Food Sci Nutr. 1992;202:307.

50. Jung KA, Song TC, Han D, Kim IH, Kim YE, Lee CH. Cardiovascular protective properties of Kiwifruit extracts in vitro. Biol Pharm Bull. 2005;28:1782-5.

51. Gholamhoseinian A, Shahowzehi B, Far FS. Inhibitory activity of some plant methanol extracts on 3-Hydroxy-3-Methylglutaryl coenzyme A reductase. Int J Pharmacol. 2010;6:705-11.

52. Qureshi AA, Burgerpll WC, Petersonpll DM, Elson CE. The structure of an inhibitor of cholesterol biosynthesis isolated from barley. J Biol Chem. 1986;261:10544-50.

53. Min SW, Kim DH. Kakkalide and irisolidone: HMG-CoA reductase inhibitors isolated from the flower of Pueraria thunbergiana. Biol Pharm Bull. 2007;30:1965-8.

54. Vallianou I, Peroulis N, Pantazis P, Cladaras HM. Camphene, a plant-derived monoterpene, reduces plasma cholesterol and triglycerides in hyperlipidemic rats independently of HMG-CoA reductase activity. PLoS One. 2011;6:11. e20516.

55. Kim HJ, Lee DH, Hwang YY, Lee KS, Lee JS. Characterization of $\beta$-Hydroxy- $\beta$ methylglutaryl Coenzyme A reductase inhibitor from Pueraria thunbergiana. J Agric Food Chem. 2005;53:5882-8.

56. Patil AD, Chan JA, Lois-Flamberg P, Mayer R, Westley JW. Novel acetylenic acids from the root bark of Paramacrolobium caeruleum: inhibitors of 3-Hydroxy-3methyl-glutaryl Coenzyme A reductase. J Nat Prod. 1989;52:153-61.

57. Kwon EK, Lee DY, Lee H, Kim DO, Baek NI, Kim YE, et al. Flavonoids from the buds of Rosa damascena inhibit the activity of 3-Hydroxy-3-methylglutarylcoenzyme A reductase and angiotensin I-converting enzyme. J Agric Food Chem. 2010;58:882-6.

58. Khan MS, Akhtar S, Al-Sagair OA, Arif JM. Protective Effect of dietary tocotrienols against infection and inflammation-induced hyperlipidemia: an in vivo and in silico study. Phytother Res. 2011;25:1586-95.

59. Khanna AK, Rizivi F, Chander R. Lipid lowering activity of Phyllanthus niruri in hyperlipidemic rats. J Ethnopharmacol. 2002;82:19-32.

60. Kuroda M, Tanzawa K, Tsujita Y, Endo A. Mechanism for elevation of hepatic cholesterol synthesis and serum cholesterol levels in Triton WR-1339 induced hyperlipidemia. Biochim Biophys Acta. 1997;489:119-25.

61. Venkadeswaran K, Muralidharan AR, Annadurai T, Ruban W, Sundararajan M, Anandhi $\mathrm{R}$, et al. Antihypercholesterolemic and antioxidative potential of an extract of the plant, Piper betle, and its active constituent, eugenol, in Triton WR-1339 induced hypercholesterolemia in experimental rats. Evid Base Complement Alternat Med. 2014;Article ID 47897:1-11. http://dx.doi.org/ 10.1155/2014/478973.

62. Schotz MC, Seanu A, Page $\mathbb{H}$. Effect of triton on lipoprotein lipase of rat plasma. Am J Physiol. 1957;188:399-402.

63. Mackness MI, Arrol S, Durrington PN. Paraoxonase prevents accumulation of lipoperoxides in low-density lipoprotein. FEBS Lett. 1991;286:152-4.

64. Watson AD, Berliner JA, Hama SY, La Du BN, Faull KF, Fogelman AM, et al. Protective effect of high density lipoprotein associated paraoxonase. Inhibition of the biological activity of minimally oxidized low density lipoprotein. J Clin Invest. 1995;96:2882-91.

65. Drexel H, Amann FW, Rentsch K, Neuenschwander C, Luethy A, Khan SI, et al. Relation of the level of high-density lipoprotein subfractions to the presence and extent of coronary artery disease. Am J Cardiol. 1992;70:436-40.

66. Downs JR, Clearfield M, Weis S, Whitney E, Shapiro DR, Beere PA, et al. Primary prevention of acute coronary events with lovastatin in men and women with average cholesterol levels. JAMA. 1998;279:1615-22. 
67. Kandutsch AA, Saucier SE. Prevention of cyclic and triton-induced increases in hydroxymethylglutaryl Coenzyme A reductase and sterol synthesis by puromycin. J Biol Chem. 1969;244:2299-305

68. Goldfarb S. Rapid increases in hepatic HMG CoA reductase activity and in vivo cholesterol synthesis after Triton WR 1339 injection. J Lipid Res. 1978;19:489-94.

69. Sashidhara KV, Singh SP, Srivastava A, Puri A, Chhonker YS, Bhatta RS, et al. Discovery of a new class of HMG-CoA reductase inhibitor from Polyalthia longifolia as potential lipid lowering agent. Eur J Med Chem. 2011;46:5206-11.

\section{Submit your next manuscript to BioMed Central} and take full advantage of:

- Convenient online submission

- Thorough peer review

- No space constraints or color figure charges

- Immediate publication on acceptance

- Inclusion in PubMed, CAS, Scopus and Google Scholar

- Research which is freely available for redistribution 